\title{
Digitization of Clinical Trials in India: A New Step by CDSCO towards Ensuring the Data Credibility and Patient Safety
}

Shubhasis Dan', Sanmay Karmakar ${ }^{1}$, Balaram Ghosh ${ }^{2}$ and Tapan Kumar Pal' ${ }^{\star}$

${ }^{1}$ Bioequivalence Study Centre, Department of Pharmaceutical Technology, Jadavpur University, Kolkata, West Bengal

${ }^{2}$ Midnapore Medical College, Govt. of West Bengal, Medinipore, West Bengal

\begin{abstract}
Supervision provides a foundation for future workers to learn practical skills from a qualified professional, and is essential for the development of a profession. Supervision is also very much essential for developing workforces. Recently CDSCO has proposed to create an IT enabled system for online submission of various information on clinical trials to streamline the process of approval, maintaining comprehensive database and monitoring The clinical trials for ensuring the protection of rights, safety and well beings of trial subjects and authenticity of the data generated. Looking at the current regulatory environment of clinical trial in India, it is very much important to collate all the information related to four major domains of clinical trial to bioequivalence study captured online in an organized manner. These domains are: Sponsor/ CRO, Investigator, Ethics Committee (EC) and Patient/ volunteer. In order to get access to all the information, all the sponsors/CROs, Investigators and Ethics Committees are required to put the information in a common repository related to a particular CT which will be updated by the stakeholders on day to day basis.
\end{abstract}

The efforts of the Indian Regulators towards ensuring the patient safety and data credibility are discussed in the present study.

Keywords: Central Drugs Standard Control Organization (CDSCO); Drugs Controller General of India (DCGI); New Drug Advisory Committees (NDACs); Technical Review Committee (TRC); Indian Council of Medical Research (ICMR); Serious Adverse Events (SAE); DSMB (Data and Safety Monitoring Board)

\section{Preface}

India is a widely preferred location for the pharmaceutical companies in conducting clinical research for several reasons, including technically competent manpower, available patient of various demographic and clinical conditions, low costs etc. These advantages have made this subcontinent one of the world's preferred destinations for clinical trials.

The growth of Indian Clinical Trial market turns down after some big controversies from 2012 onwards. There are various discrepancies reported like numerous death, unethical conductance, voids of proper regulatory permissions, trial related injury and compensations etc. Public activists (NGOs) acted as a whistle blower impinging Indian government and regulators to act promptly.

As a result noticeable reduction in number of permission of clinical trial (Figure1) is observed since last few years [1,2].

After a sharp decline in clinical trial activity in India after 2010, all stakeholders seem to agree that the key goal in conducting clinical research is patient safely and produce credible data and the Indian regulatory played the desired role to set the required standards and regulations addressing these issues.

Available regulatory guidelines for clinical research in India [3] are furnished below-

- "Schedule-Y" of the Drugs and Cosmetics Act (1940) and Rules (1945) [4]

- "Good Clinical Practices for Clinical Research in India" of CDSCO [5]

- "Ethical Guidelines for Biomedical Research on Human Participants" of Indian Council of Medical Research [ICMR]) [6].

\section{Present situation}

After these controversies the government as well as judiciary along with other stakes holders sit together to amend the old regulations which results in the long awaited development of amended regulatory affairs). Some were more progressive in comparison to the rest of the world and were more protective of the trial subjects.

- Mandatory registration of all new clinical trials in the Clinical Trials Registry of India (as of 2009) [7].

- Registration of ethics committees; and use of language encouraging respect of participants' cultural, educational, and economic backgrounds [8].

- Formation of New Drug Advisory Committees (NDACs) and Technical Review Committee (TRC).

- Audio visual recording of Informed Consent Process [9].

- Time frame of SAE reporting [8] etc.

Conducting any clinical trial in India essentially requires approval from the registered ethics committee. The DCGI will not sanction the permission to begin the study without this approval. The EC carefully reviews each of the clinical trial protocol submitted to them as per Schedule Y, the Good Clinical Practice Guidelines for Clinical Trials in India and other applicable regulatory requirements for safeguarding rights, safety and well-being of the trial subjects [8].

*Corresponding author: Tapan Kumar Pal, Emeritus Medical Scientist (ICMR) and Ex-Director, Bioequivalence Study Centre, Department of Pharmaceutical Technology, Jadavpur University, Kolkata -700 032 India, Tel: +91-9830036297; E-mail: tkpal@pharma.jdvu.ac.in

Received July 20, 2015; Accepted August 13, 2015; Published August 17, 2015

Citation: Dan S, Karmakar S, Ghosh B , Pal TK (2015) Digitization of Clinical Trials in India: A New Step by CDSCO towards Ensuring the Data Credibility and Patient Safety. Pharmaceut Reg Affairs 4: 149. doi:10.4172/2167-7689.1000149

Copyright: (c) $2015 \mathrm{Pal}$ TK, et al. This is an open-access article distributed under the terms of the Creative Commons Attribution License, which permits unrestricted use, distribution, and reproduction in any medium, provided the original author and source are credited. 


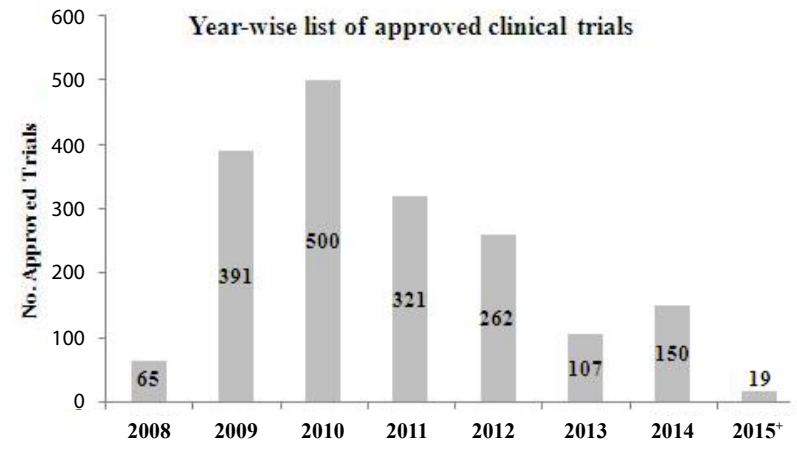

Figure 1: Year-wise number of permission of clinical trial in India (up to Apr, 2015).

With the ethical clearance and other related essential documents the sponsor prepared a dossier for the regulatory submission. In India, trial can be started only after the regulatory permission.

This result in a very lengthy turnaround times for clinical trial approvals and under-enforcement of quality standards, which are features seem to be potential to dissuade foreign sponsors to conduct clinical trials in India and may have contributed to the reduced number of clinical trials and departure of international collaborators [10-12].

\section{Initiatives taken by CDSCO}

In purview of the above, recently Ministry of Health and Family Welfare, Govt. of India took major initiatives. As a result, under the Chairmanship of Prof. Ranjit Roy Chaudhury an Expert Committee to formulate policy and guidelines for approval of new drugs, clinical trials and banning of drugs was constituted. The outcome of which must be implied by the Central Drug Standard Control Organization (CDSCO). Some of the key recommendations are $[13,14]$ :

- $\quad$ Accreditations of Ethics Committee

- Accreditations of Investigator

- Accreditations of Clinical Trial Site

- $\quad$ Procedure for review of applications of clinical trials and new drugs

- $\quad$ Computerized database and selection of experts

\section{- $\quad$ Specifying time line for processing of applications}

It is evident from the past experience that a stringent and informed review system enhances the potential for human subject protection in clinical trials. To make the clinical trial generated data credible and to be accepted without any argument, it is necessary to put that in to the public domain.

Therefore, CDSCO has decided to use Information technology [15] in every steps of a clinical trial to ensure total transparency in the system. From the first step when the application is filed, every step will be recorded and made available in the public domain. This will meet the demand of complete transparency and accountability in functioning role of CDSCO.

In order to capture exact information, all the sponsors/CROs, Investigators and Ethics Committees are required to put the information in a common repository related to a particular CT which is updated by the stakeholders on day to day basis.

The responsibility to update the information should be timebound. This will be monitored by a dedicated cell in CDSCO. The information's to be uploaded is elaborated in the (Table 1).

In case of any deviation, the regulatory authority may give instructions to put a hold on new recruitment in the trial. There will be also the provision to take action against the Sponsor/ Investigator/ EC depending upon the accountability.

\section{Conclusion}

The goal OF clinical supervision is to build and advance the clinical social worker's skills, knowledge and attitudes in order to improve client care and to enhance the professional growth and development of the clinical social worker. A participative system involving the medical community, pharmacists, industry and patients with the help of modern information technology would be beneficial for the Health and Pharmacy stake holders. The latest developments in Indian regulations reflect a concerted effort on the part of the public health community to push clinical trial issues in to a great extent. Here the Indian regulatory plays the desired role which will set the standards for conducting the clinical research in future.

The effort made by the CDSCO towards information technology enabled online process will encourage the sponsors to set their clinical research destination. On the other hand this transparent process will also satisfy the need of entire health care community (patients, researchers and activists) towards trial subject's care and safety.

\begin{tabular}{|l|l|l|}
\hline Before initiation of Trial and filing application to CDSCO & During the conduct of Trial & After completion of Trial \\
\hline $\begin{array}{l}\text { Identification of the Trial } \\
\text { (Application no., title, protocol no., etc.) }\end{array}$ & $\begin{array}{l}\text { Date of initiation } \\
\text { (Start date) }\end{array}$ & $\begin{array}{l}\text { Site wise declaration of end of the trial } \\
\text { (End date, regulatory remarks, dropout reasons, etc.) }\end{array}$ \\
\hline $\begin{array}{l}\text { Details of the sponsor } \\
\text { (Name, address, legal representative, etc.) }\end{array}$ & $\begin{array}{l}\text { Whether any DSMB appointed } \\
\text { if yes, details thereof }\end{array}$ & $\begin{array}{l}\text { Inspection details of sites } \\
\text { (Ref. no., outcome, site address, etc.) }\end{array}$ \\
\hline $\begin{array}{l}\text { Investigational product (IP) } \\
\text { (information on each investigational product being used } \\
\text { in the trial except for placebos (to be used either as test, } \\
\text { comparator or both) }\end{array}$ & (Address, contact details) & $\begin{array}{l}\text { Inspection of investigational product manufacturer/importer } \\
\text { (Ref. no., inspection outcome, etc.) }\end{array}$ \\
\hline $\begin{array}{l}\text { Description of the IP } \\
\text { (Route of administration, dose, label claims, etc.) }\end{array}$ & $\begin{array}{l}\text { Ethics committee } \\
\text { (Opinions, date, etc.) }\end{array}$ & $\begin{array}{l}\text { Patient wise details SAEs } \\
\text { (Related to the IP or not, opinions of EC, PI, sponsor, date } \\
\text { of occurrence and reporting, nominee, compensations, etc.) }\end{array}$ \\
\hline $\begin{array}{l}\text { Authorized site responsible for the release of IP } \\
\text { (Details of the accountability) }\end{array}$ & $\begin{array}{l}\text { Amendments to the protocol } \\
\text { (Date, EC recommendations, regulatory } \\
\text { permission, etc.) }\end{array}$ & $\begin{array}{l}\text { Details of trial subjects (site wise) } \\
\text { (Name, age, address, sex, nominee, enrollment } \\
\text { and randomization, etc.) }\end{array}$ \\
\hline $\begin{array}{l}\text { General information } \\
\text { (Scope, medical condition, phase, compensation policy } \\
\text { etc.) }\end{array}$ & \\
\hline
\end{tabular}


Citation: Dan S, Karmakar S, Ghosh B , Pal TK (2015) Digitization of Clinical Trials in India: A New Step by CDSCO towards Ensuring the Data Credibility and Patient Safety. Pharmaceut Reg Affairs 4: 149. doi:10.4172/2167-7689.1000149

Page 3 of 3

\begin{tabular}{|l|l|l|}
\hline $\begin{array}{l}\text { Population of trial subjects } \\
\text { (Age, sex, type, etc.) }\end{array}$ & $\begin{array}{l}\text { Details of SAEs reported (patient wise) } \\
\text { (Details of patient, opinions-EC, PI, sponsor, } \\
\text { date of occurrence, reporting, compensations, } \\
\text { etc.) }\end{array}$ & \\
\hline $\begin{array}{l}\text { Ethics committee } \\
\text { (Name, address, reg. no., minutes of meeting, members, } \\
\text { etc.) }\end{array}$ & & - \\
\hline $\begin{array}{l}\text { Investigator details } \\
\text { (Name, address, reg. No., details of GCP trainings, etc.) }\end{array}$ & & - \\
\hline $\begin{array}{l}\text { Informed consent document } \\
\text { (Fulfilling the criteria specified in Sch-Y) }\end{array}$ & & - \\
\hline
\end{tabular}

Table 1: Information's to be uploaded.

\section{Conflict of Interest}

\section{None}

\section{Acknowledgement}

Author, Shubhasis Dan is grateful to University Grants Commission (UGC), New Delhi, India for providing fellowship under UGC-BSR scheme.

\section{References}

1. (2013) Central Drugs Standard Control Organization (CDSCO), Clinical Trial Approval in 2013

2. (2014) Central Drugs Standard Control Organization (CDSCO), Clinical Trial Approval in 2014

3. Burt T, Sharma P, Dhillon S, Manchanda M, Mittal S, et.al. (2014) Clinical Research Environment in India: Challenges and Proposed Solutions. J Clin Res Bioeth 5: 1-8.

4. (2013) Central Drugs Standard Control Organization (CDSCO), Drugs and Cosmetics Rules, 1945.

5. Central Drugs Standard Control Organization (CDSCO): Good Clinical Practices for Clinical Research in India.

6. (2006) Ethical guidelines for biomedical research on human participants. New Delhi: Indian Council of Medical Research.
7. Pandey A, Aggarwal AR, Maulik M, Gupta J, Juneja A, et al. (2011) The upgraded Clinical Trials Registry India: A summary of changes. Indian J Med Ethics 8: 186.

8. Dan S, Ghosh B, Gorain B, Pal TK (2014) Mandatory Registration of the Research Ethics Committees in India. Applied Clinical Research, Clinical Trials and Regulatory Affairs 1: 88-92.

9. (2014) Central Drugs Standard Control Organization (CDSCO), Guidance for Audio Visual Recording.

10. Krishnan V, Koshy PK (2013) US agency NIH scraps nearly 40 clinical trials in India. Live Mint.

11. Brennan ZX (2014) Quintiles shutters Phase I unit in India.

12. Chatterjee S, Hirschler B (2014) Big Pharma pushes for U.S. action against India over patent worries. Reuters.

13. (2013) Actions on the recommendations of Prof. Ranjit Roy Chaudhury expert committee to formulate policy and guidelines for approval of new drugs, clinical trials and banning of drugs. Accessed from cdsco.nic.in. Action RR Choudhury_Committee.

14. Accreditation Standards for Ethics Committee, Investigator, Clinical Trial Site: National Accreditation Board for Hospitals and Healthcare Providers (NABH).

15. (2014) Central Drugs Standard Control Organization (CDSCO), Notice of proposal for creation of IT enabled system. 